\title{
Surgical radiofrequency ablation of both atria for atrial fibrillation: Results of a multicenter trial
}

\author{
Jai Raman, MBBS, MMed, FRACS, PhD ${ }^{a}$ \\ Susumu Ishikawa, $\mathrm{MD}^{\mathrm{a}}$ \\ Meg M. Storer, BN, MN ${ }^{a}$ \\ John M. Power, BVSc, PhD ${ }^{\mathrm{b}}$
}

From the Department of Cardiac Surgery, ${ }^{a}$ Austin and Repatriation Medical Centre, Heidelberg, Victoria, Australia, and the Baker Institute of Medical Research, ${ }^{\mathrm{b}}$ Prahran, Victoria, Australia.

Funds for animal research and travel grants were provided to Drs Jai Raman and John Power by EP Technologies, Boston Scientific Corporation, San Jose, Calif.

Read at the Eighty-second Annual Meeting of The American Association for Thoracic Surgery, Washington, DC, May 5-8, 2002.

Received for publication April 22, 2002; revisions requested July 8,2002 ; revisions received Sept 24, 2002; accepted for publication Nov 18, 2002.

Address for reprints: Jai Raman, MBBS, MMed, FRACS, PhD, Section of Cardiac and Thoracic Surgery, University of Chicago Medical Center, 5841 S Maryland Ave, MC 5040, Chicago, IL 60637 (E-mail: jraman@surgery.bsd.uchicago.edu).

J Thorac Cardiovasc Surg 2003;126: 1357-66

Copyright $\odot 2003$ by The American Association for Thoracic Surgery

$0022-5223 / 2003 \$ 30.00+0$

doi:10.1016/S0022-5223(03)01185-1
Background: The Cox maze procedure has shown to be effective in treating atrial fibrillation. Radiofrequency ablation, with a similar objective, has been used as an adjunct to conventional cardiac surgery for the treatment of atrial fibrillation in more than 20 centers in Australia and New Zealand since March 2000. This is a report of those results.

Methods: One hundred thirty-two patients in 20 centers underwent radiofrequency ablation as an adjunct to conventional cardiac surgery, with a standardized lesion set created with a flexible, 7-electrode, temperature-controlled probe (Cobra; EPTechnologies, San Jose, Calif). All data were entered into a central registry, with regular follow-up prompted by the registry cocoordinator. Each radiofrequency scar was made with standard parameters requiring 2 minutes of tissue coagulation at $80^{\circ} \mathrm{C}$ to $85^{\circ} \mathrm{C}$. Patients undergoing mitral procedures had radiofrequency ablation performed in the left atrium endocardially. Patients undergoing aortic valve replacement or coronary artery bypass surgery underwent epicardial radiofrequency ablation of the left atrium. Epicardial radiofrequency ablation lesions on the right atrium were common to both groups of patients. Preoperatively, $75 \%$ of the patients had chronic atrial fibrillation, $21 \%$ had paroxysmal atrial fibrillation, and $4 \%$ had flutter. Surgical procedures performed included mitral valve procedure in $60 \%$, coronary artery bypass grafting in $14 \%$, aortic valve replacement in $7 \%$, and coronary artery bypass grafting plus aortic valve replacement in $4 \%$.

Results: There were no major complications related to the use of radiofrequency ablation. There were no soft tissue or cardiac perforations. Ten patients were defibrillated into sinus rhythm within 3 months postoperatively. The freedom from atrial fibrillation was $84 \%$ at 3 months, $90 \%$ at 6 months, and $100 \%$ at 12 months. All patients at 12 and 18 months' follow-up were in sinus rhythm. There were no thromboembolic complications.

Conclusions: Surgical radiofrequency ablation can be performed safely as an adjunct to conventional cardiac surgery. A standardized lesion set created by using similar temperature settings can be adopted in multiple centers and might be effective in treating atrial fibrillation. Data collection through a central registry has helped in monitoring the effectiveness of this new technique in a scattered population.

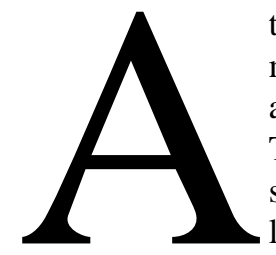
trial fibrillation (AF) is the most common of all sustained arrhythmias. ${ }^{1}$ It occurs in $6 \%$ of the population older than 65 years of age $^{2}$ and is the most frequent cause of strokes in the elderly. ${ }^{3,4}$ The role of medical therapy, whether by attempting to restore sinus rhythm ${ }^{5}$ or with anticoagulation, ${ }^{6}$ is reasonably well established. However, there is no cocoordinated surgical strategy to deal with this common problem, despite the pioneering development of a specific 
procedure by Dr James Cox for this condition (ie, the maze procedure). ${ }^{7}$ An elegant and innovative approach to $\mathrm{AF}$, this technique and its variations require multiple atrial incisions, which need to be sutured. ${ }^{8}$ These sutured incisions are full-thickness scars that act as lines of electrical block. Despite the development of the maze procedure in the late 1980 s and its propagation in the 1990 s, most cardiac surgeons have hesitated at using this technique. In part, this might be due to the perceived increased complexity and risk associated with multiple incisions in a posterior structure, such as the left atrium. ${ }^{9-11}$ Indeed, surgeons who have vigorously adopted the maze procedure have been those renowned for their skill, working in reputable centers of high volume, such as the Cleveland Clinic ${ }^{12}$ and the Mayo Clinic. ${ }^{13}$ Their results have been very good. Despite reasonably good results with the modified maze procedure performed by Dr David Johnson in Sydney in the early 1990s, the procedure was not adopted by any of the other centers in Australia or New Zealand.

We chose to replace the cut-and-sew approach with radiofrequency ablation (RFA) to create transmural lines of electrical block on the basis of animal work performed at our laboratory. ${ }^{14}$ Our early clinical experience ${ }^{15}$ helped pave the way for the adoption of RFA as an adjunct to conventional cardiac surgery in many centers across Australia and New Zealand. This is a preliminary report on this multicenter experience.

\section{Methods}

\section{Surgical Technique}

Radiofrequency lesions were created by using the flexible, 7-electrode, temperature-controlled Cobra probe (EP Technologies, Boston Scientific Corp, San Jose, Calif). Lesion creation parameters were set at $80^{\circ} \mathrm{C}$ to $85^{\circ} \mathrm{C}$ for 2 minutes to achieve transmural scars. The lesion set combined elements of the maze procedure as described by Cox and colleagues, ${ }^{16}$ the radial procedure as described by Nitta and associates, ${ }^{17}$ and the bilateral isolation of pulmonary veins as described by Melo and coworkers. ${ }^{18}$

Figure 1 shows the schematic diagram of the lesion set chosen by our group (4a being the endocardial lesions used in the mitral procedures, $1 \mathrm{~b}$ being the epicardial lesions on the left atrium used in aortic valve/coronary artery bypass grafting [CABG] procedures, and $1 \mathrm{c}$ being epicardial right atrial lesions used in both). The numbered lines are a suggested sequence of lesions meant to help with training surgeons unfamiliar with RFA of the atria, the maze procedure, or both. The steps of the procedure are described in the diagram. The left atrial appendage was oversewn in a linear fashion from within, and this plicating suture helped gather up redundant atrial tissue in this region going up to the atrial roof. Pulling up on the uncut ends of the suture also helped display the left-sided pulmonary vein orifices.

\section{Steps in Adoption of the Technique}

Patients with established AF undergoing conventional cardiac surgical procedures were considered. Patient enrollment in this expe- rience was based on the surgeon's discretion. All patients provided informed written consent. Only 3 of the participating centers required that these procedures be ratified by an institutional review board. With the advent of strict privacy laws in Australia in mid-2001, it was mandatory for all patients to consent separately for inclusion of their names and records in a central database.

In the first half of our experience, all patients had AF documented on a preoperative 24-hour Holter electrocardiographic monitor, before being offered RFA. Initially, the procedure was performed only in association with mitral valve surgery. The RFA procedure was also used in such a way that there was no significant alteration of the surgeon's current approach and technique.

Safety precautions were prescribed and consisted of the following:

1. Adequate placement of adhesive grounding pads was used to ensure proper creation of radiofrequency lesions.

2. Withdrawal of the transesophageal echocardiographic probe from the mid-esophagus and turning off of the echocardiographic machine were used to minimize the risk of esophageal injury. The lesion set in the posterior left atrium also avoided the most dependant portion of the left atrium, which was likely to be in contact with the esophagus.

3. If the probe shut off, the system was shut down and restarted. This was to avoid overheating the tissue.

4. The probe was always placed under direct vision or by means of palpation, with care taken to ensure tissue contact. This was done to avoid collateral damage in surrounding structures and to ensure accurate lesion creation.

5. Lesions were created close to the circumflex artery within the left atrium with infusion of cardioplegia. Lesions close to the right coronary artery on the right atrioventricular groove were created with the heart beating. This was primarily to avoid injury to the relevant coronary arteries. In addition, if the right coronary artery was large and mobile, this was dissected gently and pushed anteriorly out of the way of the probe.

6. Surgeons were also asked to watch the change in atrial tissue color with the application of the radiofrequency energy.

\section{Epicardial Applications}

As confidence in the technique grew and evidence of the transmural nature of the epicardial lesions was established, surgical RFA was extended to patients undergoing aortic valve procedures and coronary artery surgery. Epicardial lesions were created in these patients. All procedures were performed with aid of cardiopulmonary bypass. In the epicardial setting, all lesions were created during cardiopulmonary bypass. In the early part of the experience, the posterior left atrial lesions were created on an arrested heart to facilitate access. Later in the experience, the trend was to perform these lesions on a decompressed heart during $\mathrm{CPB}$, either with the aid of a left ventricular vent or bicaval cannulation. The fat pad around the pulmonary veins was dissected until the underlying muscle was seen. Unfortunately, this meant that the epicardial lesions in the posterior left atrium did not reach the mitral valve annulus. The lesion to the tricuspid valve annulus was performed low down on the anterior aspect of the right atrioventricular groove. If required, the right coronary artery was dissected free 

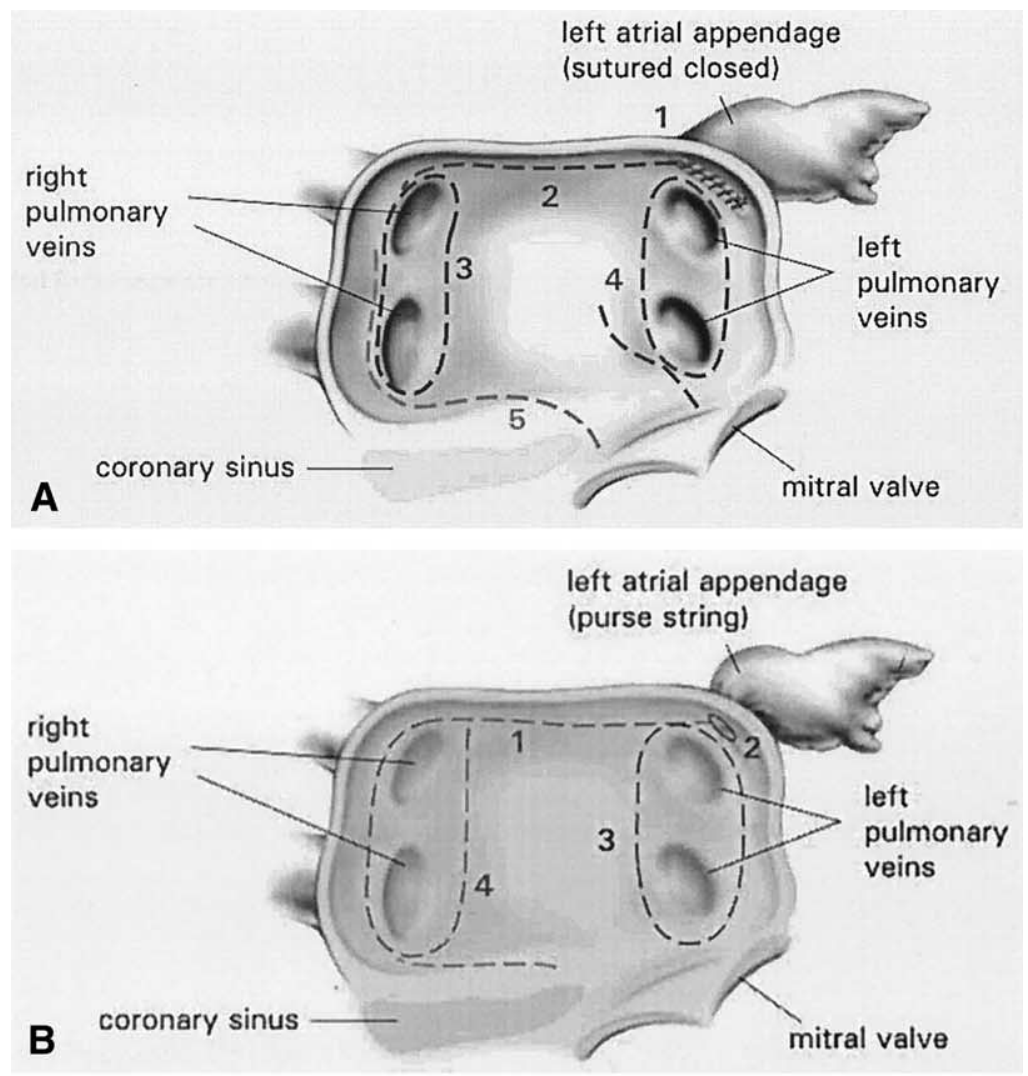

left atrial appendage (purse string)

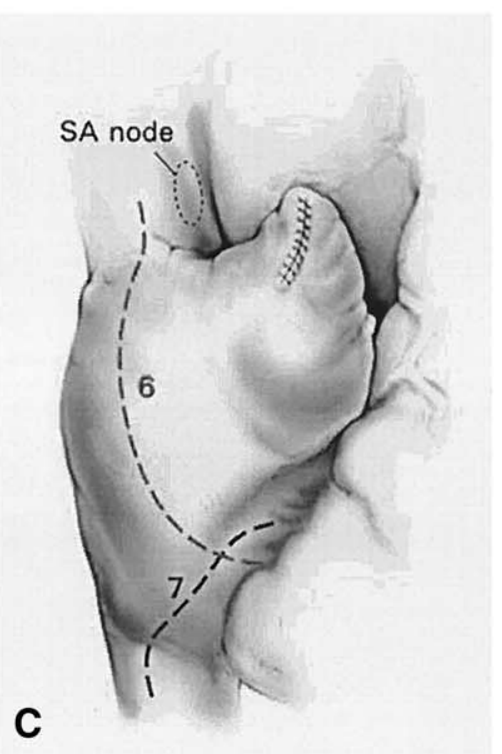

Figure 1. A, Left endocardial lesion set with mitral procedures: step 1, closure of the left atrial appendage from within; step 2, linear lesion along the roof of the left atrium; step 3, encircling lesion around right-sided pulmonary veins; step 4, encircling lesion around left-sided pulmonary veins with connecting lesion to mitral valve annulus; step 5, connecting lesion to mitral annulus from lower right pulmonary vein orifice. $B$, Left atrial epicardial lesion set with aortic valve or CABG: step 1, linear lesion along the roof of the left atrium; step 2, ligation of the base of the left atrial appendage from the outside; step 3, encircling lesions around left-sided pulmonary veins; step 4, encircling lesions around right-sided pulmonary veins with a connecting lesion toward the atrioventricular groove. $C$, Common epicardial lesion on the right atrium: step 6, linear epicardial lesion from behind the sinoatrial node approximately along the direction of the crista terminalis, curving up to the atrioventricular groove; step 7, connecting lesion from the inferior vena caval orifice to the right atrioventricular groove low on the body of the right atrium. 
TABLE 1. Patient demographics

\begin{tabular}{lc}
\hline Characteristic & No (\%) \\
\hline No. of patients & 132 \\
Age, y & $66 \pm 12$ [range, 21-86] \\
Sex, M/F & $91 / 41(69 / 31)$ \\
Preoperative rhythm & \\
Chronic AF & $99(75)$ \\
Paroxysmal AF & $28(21)$ \\
Atrial flutter & $5(4)$ \\
Surgical procedure & \\
Endocardial RFA on LA & $92(70)$ \\
Isolated mitral valve & $62(47)$ \\
Mitral valve + CABG & $10(8)$ \\
AVR + MV procedure & $7(5)$ \\
CABG + ASD closure & $1(0.7)$ \\
Redo Ebstein repair & 1 \\
Other & $11(8.3)$ \\
Epicardial RFA on LA & $40(30)$ \\
CABG & $19(14)$ \\
AVR & $9(7)$ \\
AVR + CABG & $5(4)$ \\
Other & $7(5.3)$
\end{tabular}

$\overline{L A \text {, Left atrium; } A V R \text {, aortic valve replacement; } A S D \text {, atrial septal defect. All }}$ numbers are actual figures and figures in parentheses are percentages.

and pushed anteriorly to allow the probe to sit at the atrioventricular groove.

There were no stand-alone procedures performed for AF alone.

When each new surgeon and center was trained in the use of the probe, care was taken to ensure uniformity of the lesion sets and parameters used to create them.

Details of all patients who had the procedure performed with the Cobra probe were entered into a centrally maintained registry. The purchase price of each probe also included a fee to help with the set-up and running costs of the registry. A protocol of clinical, echocardiographic, and electrocardiographic follow-up was suggested to each of the participating surgeons.

\section{Study Population}

All patients underwent a definite cardiac surgical procedure, which was the primary indication for surgical intervention. Patients were referred for surgical intervention by their cardiologists, and the decision to proceed was taken in consultation with the cardiac surgeon. Although the addition of RFA to the procedure did increase operative time, it was perceived by most participating surgeons as relatively innocuous. If there was a history of AF, random 24-hour Holter monitoring was performed, and the patient was offered RFA. All surgical RFA procedures were performed as an adjunct to conventional cardiac surgical procedures with the aid of cardiopulmonary bypass. All patients who underwent RFA were included in this study, irrespective of the risk and urgency of the procedure.

One hundred thirty-two patients underwent surgical RFA procedures between March 2000 and March 2002 at 20 hospitals across Australia and New Zealand. Table 1 outlines the patient demographics of this study. The mean age of these patients was 66 years (range, 21-86 years). Preoperatively, $75 \%$ of the patients had chronic $\mathrm{AF}, 21 \%$ had paroxysmal $\mathrm{AF}$, and $4 \%$ had a combination of flutter and fibrillation. The mean duration of preoperative rhythm disturbance was 36 months, ranging from 1 to 120 months. Although the recommendation was to apply this procedure in patients with long-standing AF (ie, duration $>6$ months), the multicenter nature of this experience placed the onus of patient enrollment on the surgeon's discretion and judgment. Almost all of the patients had clinically documented AF for more than 6 months. This report includes all the patients recruited, regardless of indication, and is a true warts and all account.

No patient's record was left out if the selection of the procedure was inappropriate.

The primary surgical procedures were mitral valve procedures in 62 patients. Mitral valve procedures and CABG were performed in 10 patients. Combined aortic and mitral procedures were performed in 7 patients. CABG was performed in 19 patients. Aortic valve procedures were performed in 9 patients. In total, endocardial RFA on the left atrium was performed in 92 patients, and epicardial RFA on the left atrium was applied in 40 patients.

\section{Pharmacologic Protocol}

Postoperatively, patients were not started on any specific regimen of anticoagulation. However, as the multicenter experience began, patients were encouraged to take low-dose amiodarone $(200 \mathrm{mg} / \mathrm{d})$ for 6 months unless specifically contraindicated.

\section{Statistical Analysis}

Statistical analysis was conducted with SAS version 5.0 software (SAS Institute, Inc, Cary, NC). Continuous data were expressed as means $\pm \mathrm{SD}$. The Student $t$ test and $\chi^{2}$ test were used for statistical analysis.

\section{Results \\ Operative Results}

There were no intraoperative atrial perforations or perioperative tissue perforations in this series. All patients were weaned off cardiopulmonary bypass in a regular sinus or paced rhythm. Initially with the mitral procedures, surgeons on their learning curve took about 20 minutes of extra crossclamp time to create the lesions. With practice, this could be reduced to approximately 12 to 14 minutes.

There were 9 perioperative deaths. None were related to the use of RFA. One was due to remote aortic dissection in a patient who had replacement of the ascending aorta. Another was due to severe liver dysfunction caused by coagulopathy and tamponade in an elderly woman with a very fragile and calcified aortic root that leaked after valve replacement. The third was a decompensated patient on a balloon pump with uncontrolled AF, who had a very poor ventricle caused by large infarcts, severe aortic regurgitation, and uncontrolled tachycardia. He arrested soon after anesthetic induction and was salvaged. RFA was used in this patient to achieve good rate control and in the hope of avoiding amiodarone. Despite a relatively stable postoperative course, there was no recovery of ventricular function on day 5, and prolonged mechanical support was not an option. In retrospect, this patient should have had another 


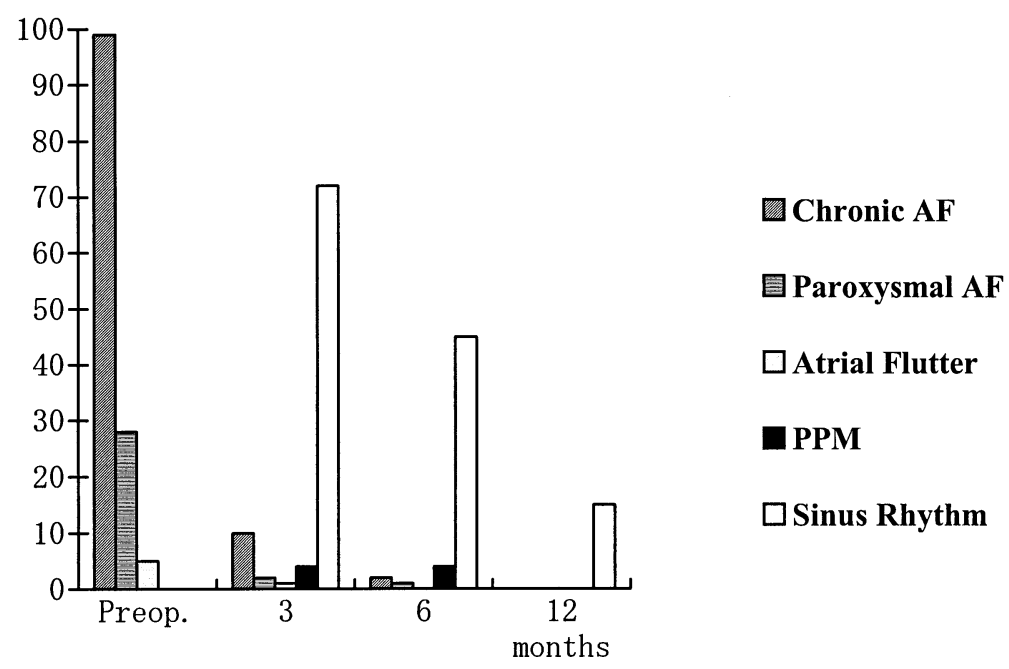

Figure 2. Rhythm profile preoperatively and postoperatively ( $=132$ patients). PPM, Permanent pacemaker.

means of rate control. However, the radiofrequency lesions were created with the heart beating on CPB, with no addition to the crossclamp time. A fourth patient died on the eighth postoperative day at home from a hemorrhaging duodenal ulcer. There was one death caused by cardiogenic shock as a result of a large infarct complicating a delayed low-output syndrome on day 6 after the operation. In this instance the infarct was septal and related to a very diseased left anterior descending artery. It is unlikely that radiofrequency energy was applied close to the left anterior descending artery. There was one death caused by perioperative gut ischemia in a patient who underwent successful mitral valve repair and CABG. One patient with a very poor ventricle who had mitral valve repair for severe regurgitation died of a postoperative low systemic vascular resistance syndrome resistant to norepinephrine and vasopressin. Details on 2 other deaths were sketchy but related to postoperative low-output states in elderly patients.

We attempted to study a control group of patients with preexisting AF who had cardiac surgery but did not have any antiarrhythmic procedures. However, this proved extremely difficult in a multicenter setting and was abandoned.

Although the recommendation was that patients continue to receive amiodarone for 6 months, there was variable compliance by treating surgeons and patients

\section{Follow-up}

From a total of 132 patients undergoing the procedure, follow-up was attempted in the 123 survivors. Twelve patients had undergone operations within 3 months of this publication and hence were not available for out-of-hospital follow-up. Mean follow-up was 6.4 months (range, 3-24 months), with complete clinical review in 110 patients.
Eighty-seven patients underwent the follow-up evaluation for 3 months, 50 for more than 6 months, and 15 for more than 12 months. Follow-up data at 6 months were not yet available in another 12 patients. Figure 2 is a representation of rhythm preoperatively and postoperatively in the patients enrolled in the study. The sinus recovery rate was $84 \%$ at 3 months ( 72 of 87 ), $90 \%$ at 6 months ( 45 of 50 ), and $100 \%$ at 12 months. Ten patients required cardioversion postoperatively. Five of them had cardioversion within 2 weeks, and 5 had cardioversion within 3 months. Recovery of sinus rhythm occurred in 9 (90\%) of these patients. In the follow-up period, return to sinus rhythm was documented by means of electrocardiography and Holter monitoring, which was usually performed between 3 and 6 months postoperatively. No stress tests were performed to examine sinus node function.

Dual-chamber pacemakers were implanted in 4 patients. One of them underwent a redo repair of an Ebstein anomaly with a modified Danielson approach in which there was significant fibrous reaction around the triangle of Koch. Another had idiopathic viral cardiomyopathy 3 months after the operation and required mechanical ventricular support for 7 days. She had sinus bradycardia after that illness, and a rate-responsive pacemaker was implanted in an effort to improve her exercise tolerance. A third patient had a transseptal approach for a mitral valve repair, and a pacemaker was implanted on day 4 for persistent atrioventricular block. The fourth patient with coronary artery disease had implantation of a pacemaker 6 months postoperatively for sick sinus syndrome. Table 2 looks at the recovery of sinus rhythm on the basis of the type of preoperative rhythm (ie, chronic vs episodic AF). Although there were fewer patients with episodic AF, their sinus recovery rates tended to be higher. Table 3 examines the effect of the type of left atrial 
TABLE 2. Effect of preoperative rhythm on recovery of sinus rhythm

\begin{tabular}{lcc}
\hline Preoperative rhythm & $\begin{array}{c}\text { Follow-up rhythm } \\
\text { at } \mathbf{3} \text { mo }\end{array}$ & $\begin{array}{c}\text { Follow-up rhythm } \\
\text { at } \mathbf{6} \text { mo }\end{array}$ \\
\hline Chronic AF & $53 / 64(83 \%)$ & $30 / 37(81 \%)$ \\
Paroxysmal AF & $18 / 21(86 \%)$ & $12 / 12(100 \%)$ \\
\hline
\end{tabular}

TABLE 3. Return to sinus rhythm on the basis of type of left atrial lesion

\begin{tabular}{lcc}
\hline $\begin{array}{l}\text { Type of left atrial } \\
\text { lesions }\end{array}$ & Sinus rhythm at $\mathbf{3}$ mo & Sinus rhythm at $\mathbf{6}$ mo \\
\hline Endocardial & $54 / 66(82 \%)$ & $35 / 39(90 \%)$ \\
Epicardial & $18 / 21(86 \%)$ & $10 / 11(91 \%)$ \\
\hline
\end{tabular}

lesion, whether endocardial or epicardial, on the recovery of sinus rhythm. The type of lesion did not cause a significant difference in the recovery of sinus rhythm.

"Atrial contractility" is a term that is used often but can be difficult to quantify. Spectral velocities across the mitral valve have been used to calculate $\mathrm{E}$ - and $\mathrm{A}$-wave values. Table 4 shows the spectral mitral velocities and the diameters of the left atria in the patients followed up at a mean of 3 months. These calculations might not have much value in the presence of a mitral valve prosthesis or a repaired mitral valve. There were no thromboembolic complications recorded in these patients.

Patients were not anticoagulated unless required, such as in the case of a mechanical valve implant. Thirty-two (26\%) patients were taking oral warfarin for the implantation of a mechanical valve. Eight patients had implantation of a biologic prosthetic valve that obviated the use of warfarin. All patients not receiving warfarin were taking low-dose aspirin. Careful review of the database suggested that the participating surgeons had varying attitudes toward anticoagulation for postoperative $\mathrm{AF}$, and the use of anticoagulation in this setting was not uniformly recorded or reported. Antiarrhythmic drugs were often only used if the patients were in recurrent AF. Similarly, interval episodes of early fibrillation after discharge from the hospital could not be tracked unless they were clinically significant or the patients reported it on their own. Routine follow-up visits were organized at 6 weeks and 3, 6, and 12 months postoperatively.

There were 6 readmissions with recurrent AF, sinus bradycardia, or both in the first 3 months postoperatively. There was one late death in a patient who had infective endocarditis complicated by liver failure 8 months postoperatively.

\section{Discussion}

The maze procedure remains the gold standard in terms of surgical therapy for AF, with excellent results reported by
TABLE 4. Echocardiographic features

\begin{tabular}{lcc}
\hline & Endocardial RFA & Epicardial RFA \\
\hline $\begin{array}{l}\text { Preoperative } \\
\quad \text { Left atrial diameter (mm) }\end{array}$ & $54 \pm 3$ & \\
Postoperative & & $45 \pm 4$ \\
$\quad$ Left atrial diameter (mm) & $49 \pm 7$ & $48 \pm 1$ \\
$\quad$ Peak E velocity (m/s) & $1.88 \pm 0.66^{*}$ & $0.47 \pm 0.3^{*}$ \\
Peak A velocity (m/s) & $0.32 \pm 0.02$ & $0.39 \pm 0.12$ \\
\hline
\end{tabular}

Endocardial, Endocardial RFA on left atrium; Epicardial, epicardial RFA on left atrium; Peak E velocity, peak transmitral early diastolic filling velocity; Peak $A$ velocity, peak transmitral atrial filling velocity.

${ }^{*} P<.05$ denotes the difference between endocardial and epicardial groups.

Cox and colleagues. ${ }^{19}$ A few other selected groups have replicated similar results. ${ }^{20,21}$ However, most of these series of patients have been performed only for AF. In the setting of mitral valve surgery or other cardiac surgical procedures, many surgeons are reluctant to use the maze procedure because of increases in crossclamp time and operative risks. ${ }^{9}$ Although many publications about the maze procedure talk about its efficacy in controlling AF, there is little mention in the surgical literature of the morbidity associated with the procedure. Indeed, in many instances anecdotal experiences are recounted informally by surgeons and surgical trainees about perioperative bleeding and longer procedure times associated with the procedure. This might be why the maze procedure has not enjoyed more widespread surgical acceptance.

In the race to create scars of electrical block, a range of different energy sources is being tested. RFA, which uses a form of alternating current, causing tissue coagulation by means of resistive heating, has been adapted from the electrophysiologist's repertoire. ${ }^{22}$ Cardiac electrophysiologists work from the endocardial aspect, causing focal ablation of ectopic foci of atrial tissue, especially in the pulmonary vein orifices. ${ }^{23}$ These techniques are limited by swirling blood that reduces energy delivery and poor geographic localization, relying on intracardiac echocardiography. To reduce the risk of thromboembolism and to allow for maximal focal delivery of radiofrequency energy, most electrophysiologists rely on temperature settings at a maximum of $70^{\circ} \mathrm{C}$ for less than 60 seconds. Their goal also is to cause focal ablation endocardially. This approach cannot be used for the treatment of AF. ${ }^{24}$

Surgical goals in the treatment of $\mathrm{AF}$ are different. If the principles of the maze procedure are to be emulated or replicated without cutting and sewing, transmural scars that act as lines of electrical block are required. Surgeons performing a combined surgical procedure have little time to measure electrograms or study maps intraoperatively to ensure transmurality. ${ }^{25}$ Patwardhan and associates ${ }^{26}$ used radiofrequency microbipolar coagulation in an early attempt 
TABLE 5. Patient characteristics in published series of maze procedures

\begin{tabular}{|c|c|c|c|c|c|}
\hline \multirow[b]{2}{*}{ Author and Center } & \multicolumn{3}{|c|}{ Concomitant surgery } & \multirow[b]{2}{*}{ Mortality } & \multirow[b]{2}{*}{ Sinus rhythm } \\
\hline & No. of patients & performed & Age (y) & & \\
\hline Cox 39 & 299 & $83(28 \%)$ & $?$ & $6 \%$ & $\sim 95 \%$ \\
\hline Doty (LDS, Utah) ${ }^{40}$ & 99 & $78(78 \%)$ & $62.9 \pm 10$ & 0 & $87 \%$ \\
\hline Schaff (Mayo Clinic) ${ }^{41}$ & 173 & $114(66 \%)$ & 60 & $1.2 \%$ & $80 \%$ \\
\hline McCarthy (Cleveland Clinic) ${ }^{42}$ & 83 & $60(72 \%)$ & $59 \pm 10$ & $1 \%$ & $90.4 \%$ \\
\hline Sie (Maastricht) ${ }^{4 *}$ & 122 & $100 \%$ & $69 \pm 10$ & $4.1 \%$ & $77 \%$ \\
\hline Australasian multicenter study* & 132 & $100 \%$ & $67 \pm 11$ & $6.8 \%$ & $90 \%$ \\
\hline
\end{tabular}

*RFA experience, as opposed to the cut-and-sew maze procedure from the other centers.

to perform a maze modification. While pioneering RFA for $\mathrm{AF}$, Melo and coworkers ${ }^{27}$ used parameters set by the cardiac electrophysiologists, causing lesions that might not have been quite transmural. That might explain the mediocre results obtained in his early reports. Numerous authors have described the creation of transmural lesions with surgical probes used for RFA. ${ }^{28,29}$ The Cobra probe specifically has been shown to create transmural lesions when used appropriately in animals. ${ }^{30}$

Our experience with the Cobra probe and its predecessor was in the animal laboratory. Quite by accident, we discovered that transmural lesions could be achieved consistently only by using a temperature setting of $80^{\circ} \mathrm{C}$ to $85^{\circ} \mathrm{C}$ for 120 seconds. We did not publish this information separately, but part of it is lost in the detail of some experimental work on a model of atrial flutter in sheep. ${ }^{12}$ This feedback, however, does not seem to have been relayed to other users of this technology. When the Australasian multicenter study got underway, rigorous attempts were made to ensure that the probe was used accurately, appropriately, and safely, with fixed parameters. Because the goal is creation of transmural scars created by coagulation of atrial tissue, it might be time to replace the term "RFA" with "radiofrequency coagulation" when used surgically.

In this context, while transmural scars are being created, the potential for collateral damage, such as esophageal injury, exists, as reported by Gillinov and colleagues ${ }^{31}$ and Mohr and associates. ${ }^{32}$ The lack of major tissue perforations in this multicenter experience, which included the learning curve, might be partly due to the rigorous adherence of the various surgeons to the protocol. The reinforcement by representatives of the probe manufacturers also helped maintain safety standards.

In a very timely editorial, $\operatorname{Cox}^{33}$ reminded us that there were too many variables, ranging from lesion patterns to the kind of energy types and settings, in the adaptation of a variety of energy sources, including RFA, in the race to replace the maze procedure. It has been difficult to delineate the benefits of one technique over another. In addition, the majority of the reports seem to emanate from one center that specializes in the application of that particular technique. Table 5 compares patient profiles, mortalities, and numbers of patients undergoing concomitant procedures in the recent literature, citing large, single-center maze experiences and one single-center radiofrequency experience for comparison.

Although the maze procedure has not been proposed for the problem of flutter, at least one report mentions its use for the treatment of atrial flutter. ${ }^{34}$

The longer-term follow-up from the Australasian registry is important in this respect because it will focus on the results of a specific pattern of lesions that have been created by fairly uniform settings of radiofrequency energy in multiple centers. The early results with this technique across Australia and New Zealand have been safe and satisfactory. Similar to the experience in Berlin, ${ }^{35}$ our follow-up showed a steady improvement over time in recovery of sinus rhythm. This also suggests that early susceptibility to AF after cardiac surgery is not significantly changed by RFA. Interestingly, the kind of left atrial lesions did not significantly alter the recovery of sinus rhythm. Patients with preoperative paroxysmal AF showed trends toward better recovery of sinus rhythm, and this might again be a reflection of smaller atria with focal triggers.

"Atrial transport function" is a term used freely in most publications about the maze procedure and its modifications. There is a great emphasis on transmitral Doppler velocities across the mitral valve. ${ }^{36,37}$ However, as most echocardiocardiologists point out, these velocities and ratios are imprecise markers of atrial function and might be quite fallacious in the setting of prosthetic mitral valves or mitral valve repairs. ${ }^{38}$ The left atrial appendage is overseen or obliterated, and the emptying velocity of the appendage, which is often used to measure atrial transport, cannot be used. Some echocardiologists have suggested using atrial diastolic and systolic volumes. However, echocardiographic assessment of these volumes can be variable and very operator dependant. These measurements would be more accurate when assessed by means of magnetic resonance imaging. These are areas that need more discussion and investigation. The difference in E/A ratios in the endocardial versus epicardial group might reflect the difference in atrial size in the 2 groups. The other important feature in the follow-up of the Australasian registry patients was the lack 
of any significant thromboembolic complications, which could be a clinical surrogate for atrial transport function.

Finally, maintaining a registry of this size requires a significant financial commitment and a good registry cocoordinator in addition to regular surgical audits and the cooperation of surgeons. It is our sincere hope that this registry can be continued in the present form at least for the next few years to establish the long-term results of surgical RFA/radiofrequency coagulation in the treatment of AF.

We acknowledge the tireless efforts of Meg Storer and all the physicians' secretaries who facilitated follow-up through the registry and Deirn Geard who helped fund and run the registry. The surgeons who contributed to this series of patients have been tremendously cooperative, and we thank them profusely. They include Drs Aubrey Almeida, Anand Dixit, Ben Bidstrup, Richard Chard, Michael Gardner, Hugh Wolfenden, Harsh Singh, Tevor Fayers, Ian Gilfillan, Jacob Goldstein, Terrence Mau, George Matalanis, Mark Murton, Michael Gardner, Ian Nicholson, Alexander Rosalion, Robert Tam, Peter Tesar, Gil Shardey, Siven Seevanayagam, and Julian Smith. It is our hope that in the future, publications from this group will be published in the format of a multicenter cooperative study.

\section{References}

1. ACC/AHA/ESC guidelines for the management of patients with atrial fibrillation: executive summary. Circulation. 2001;104:2118-50.

2. Martin A, Benbow LJ, Butrous GS, et al. Five-year follow-up of 101 elderly patients by means of long-term ambulatory cardiac monitoring. Eur Heart J. 1984;5:592-6.

3. Treseder AS, Sastry BS, Thomas TP, et al. Atrial fibrillation and stroke in the elderly hospitalized patients. Age Aging. 1986;15:89-92.

4. Wolf PA, Abbott RD, Kannel WB. Atrial fibrillation as an independent risk factor for stroke: the Framingham Study. Stroke. 1991;22:983-8.

5. Hohnloser SH, Kuck KH. Atrial fibrillation-maintaining sinus rhythm versus ventricular rate control: the Pharmacological Intervention in Atrial Fibrillation (PIAF) trial. J Cardiovasc Electrophysiol. 1998;9(suppl):S121-6.

6. Adjusted-dose warfarin versus low-intensity, fixed dose warfarin plus aspirin for high-risk patients with atrial fibrillation: Stroke Prevention in Atrial Fibrillation III Randomised Clinical Trial. Lancet. 1996;348: 633-8.

7. Cox JL, Schuessler RB, Boineau JP. The development of the maze procedure for the treatment of atrial fibrillation. Semin Thorac Cardiovasc Surg. 2000;12:2-14.

8. Cox JL, Schuessler RB, D'Agostino HF Jr, et al. The surgical treatment of atrial fibrillation: III. Development of a definitive surgical procedure. J Thorac Cardiovasc Surg. 1991;101:569-83.

9. Melo JQ, Neves J, Abecasis LM, Adragao P, Ribeiras R, SeabraGomes R. Operative risks of the maze procedure associated with mitral valve surgery. Cardiovasc Surg. 1997;5:112-6.

10. Raanani E, Albage A, David TE, Yau TM, Armstrong S. The efficacy of the Cox-maze procedure combined with mitral valve surgery: a matched control study. Eur J Cardiothorac Surg. 2001;19(4):438-42.

11. Kim KB, Huh JH, Kang CH, Ahn H, Sohn DW. Modification of the Cox-maze III procedure. Ann Thorac Surg. 2001;71(3):816-22.

12. McCarthy PM, Gillinov AM, Castle L, Chung M, Cosgrove DM. The Cox-maze procedure: the Cleveland Clinic experience. Semin Thorac Cardiovasc Surg. 2000;12:25-9.

13. Schaff HV, Dearani JA, Daly RC, Orszulak TA, Danielson GK. Cox-maze procedure for atrial fibrillation: Mayo Clinic experience. Semin in Thorac Cardiovasc Surg. 2000;12:30-7.
14. Morton J, Byrne MJ, Raman JS, Kalman JM. Electrical remodeling of the atrium in an anatomic model of atrial flutter: relationship between substrate and triggers for conversion to atrial fibrillation. Circulation. 2002;10-5(2):258-64.

15. Raman JS, Seevanayagam S, Storer M, Power JM. Combined endocardial and epicardial radiofrequency ablation of right and left atria in the treatment of atrial fibrillation. Ann Thorac Surg. 2001;72(suppl): S1096-9.

16. Cox JL, Jaquiss RD, Schuessler RB, Boineau JP. Modification of the maze procedure for atrial flutter and atrial fibrillation. II. Surgical technique of the maze III procedure. $J$ Thorac Cardiovasc Surg. 1995;110:485-95.

17. Nitta T, Lee R, Schuessler RB, Boineau JP, Cox JL. Radial approach: a new concept in surgical treatment of atrial fibrillation. I. Concept, anatomic and physiologic bases and development of a procedure. Ann Thorac Surg. 1999;67:27-35.

18. Melo JQ, Adragao P, Neves J, et al. Surgery for atrial fibrillation using radio-frequency catheter ablation: assessment of results at one year. Eur J Cardiothorac Surg. 1999;15:851-5.

19. Cox JL, Schuessler RB, Lappas DG, Boineau JP. An $81 / 2$ year clinical experience with surgery for atrial fibrillation. Ann Surg. 1996;224:26775 .

20. Jessurun ER, Hemel HM, Defauw JAMT, et al. Results of maze surgery for lone paroxysmal atrial fibrillation. Circulation. 2000;101: 1559-67.

21. Bauer EP, Szalay ZA, Brandt RR, et al. Predictors of atrial transport function after mini-maze operation. Ann Thorac Surg. 2001;72:1251-5.

22. Jackman WM, Beckman KJ, McClelland JH, et al. Treatment of supraventricular tachycardia due to atrioventricular nodal re-entry, by radiofrequency catheter ablation of slow pathway conduction. $N$ Engl J Med. 1992;327:313-8.

23. Haissaguerre M, Jais $\mathrm{P}$, Shah DC, et al. Right and left atrial radiofrequency catheter therapy of paroxysmal atrial fibrillation. J Cardiovasc Electrophysiol. 1996;7:1132-44.

24. Lustgarten DL, Soector PS. Ablation strategies reflect evolving concepts of atrial fibrillation mechanisms. J Electrocardiol. 2001; 34(suppl):129-34.

25. Avitall B, Gupta G, Bharati S. Are trans-mural contiguous lesions essential? Post-atrial fibrillation ablation: lesion morphology versus outcome [abstract]. J Am Coll Cardiol. 1998;31:367A.

26. Patwardhan AM, Dave HH, Tamhane AA, et al. Intra-operative radiofrequency micro-bipolar coagulation to replace incision of maze III procedure for correcting atrial fibrillation with rheumatic valvular disease. Eur J Cardiothorac Surg. 1997;12:627-33.

27. Melo J, Adragao P, Neves J, et al. Endocardial and epicardial radiofrequency ablation in the treatment of atrial fibrillation with a new intra-operative device. Eur J Cardiothorac Surg. 2000;18:182-6.

28. Viola N, Williams MR, Oz MC, et al. The technology in use for the surgical ablation of atrial fibrillation. Semin Thorac Cardiovasc Surg. 2002;14(3):198-205.

29. Shimoike E, Kaji Y, Ueda N, Maruyama T, kanaya S, Niho Y. In vivo and in vitro study of radio-frequency application with a new long linear probe: implication for the maze operation. J Thorac Cardiovasc Surg. 2000;120(1):164-72.

30. Kress DC, Krum D, Chekanov V, et al. Validation of a left atrial lesion pattern for intra-operative ablation of atrial fibrillation. Ann Thorac Surg. 2002;73(4):1160-8.

31. Gillinov AM, Pettersson G, Rice TW. Esophageal injury during radiofrequency ablation for atrial fibrillation. J Thorac Cardiovasc Surg. 2001;122(6):1239-40.

32. Mohr FW, Fabricius AM, Falk V, et al. Curative treatment of atrial fibrillation with intra-operative radiofrequency ablation. J Thorac Cardiovasc Surg. 2002;123(5):914-27.

33. Cox JL. Intraoperative options for treating atrial fibrillation associated with mitral valve disease. J Thorac Cardiovasc Surg. 2001;122:212-5.

34. Dakik HA, Arnaout S, Khoury M, et al. Cox-maze procedure for treatment of atrial flutter associated with an atrial septal defect. Clin Cardiol. 2000;23(7):548-9. 
35. Pasic M, Berg P, Muller P, et al. Intra-operative radiofrequency maze ablation for atrial fibrillation: the Berlin modification. Ann Thorac Surg. 2001;72:1484-90.

36. Lonnerholm S, Blomstrom P, Nilsson L, Oxelbark S, Jideus L, Blomstrom-Lundqvist C. Atrial size and transport function after the maze II procedure for paroxysmal atrial fibrillation. Ann Thorac Surg. 2002; 73:107-11.

37. Lee JW, Choo SJ, Kim KI, et al. Atrial fibrillation surgery simplified with cryo-ablation to improve left atrial function. Ann Thorac Surg. 2001;72:1479-83.

38. Stevenson JG, Otto CM. Impact of color flow Doppler physics on clinical assessment of flow abnormalities. In: Otto CM, editor. The Practice of Clinical Echocardiography. Philadelphia: WB Saunders; 1997. p. 291-306

39. Cox JL, Ad N, Palazzo T, Fitzpatrick S, Suyderhoud JP, DeGroot KW, et al. Current status of the maze procedure for the treatment of atrial fibrillation. Semin Thorac Cardiovasc Surg. 2000;12:15-9.

40. Arcidi JM, Doty DB, Millar RC. The maze procedure: The LDS Hospital experience. Semin Thorac Cardiovasc Surg. 2000;12:38-43.

41. Schaff JV, Dearani JA, Daly RC, Orzulak TA, Danielson GK. Coxmaze procedure for atrial fibrillation: Mayo Clinic experience. Semin Thorac Cardiovasc Surg. 2000;12:30-7.

42. McCarthy PM, Gillinov MA, Castle L, Chung M, Cosgrove D. The Cox-maze procedure: The Cleveland Clinic experience. Semin Thorac Cardiovasc Surg. 2000;12:25-9.

43. Sie HT, Beukema WP, Misier ARM, Elvan A, Ennena JJ, Haalebos MM, et al. Radiofrequency modified maze procedure in patients with atrial fibrillation undergoing concomitant cardiac surgery. $J$ Thorac Cardiovasc Surg. 2001;122:249-56.

\section{Discussion}

Dr J. Cox (Washington, DC). Dr Raman and his colleagues at the other 19 hospitals in this multicenter study are to be commended for achieving these rather striking results, especially the $100 \%$ cure rate of $\mathrm{AF}$ at 12 and 18 months. When I first read these results several weeks ago, I had difficulty believing them. However, on closer inspection, I think it is clear that the explanation for these remarkable results resides in the design criteria of the multicenter study.

As Dr Raman pointed out, the 2 principles to which all the participants adhered in this study were that the pattern of lesions would correspond as closely as possible to those of either the maze or radial procedures, both of which are proved procedures, and that every effort would be made to be certain that every portion of every lesion was transmural.

By adhering to these 2 fundamental principles, the results could have been predicted, I think, because every previous study that has taken this approach has resulted in essentially the same results. This strongly implies, though, that as long as the lesion pattern is correct and the lesions are transmural, the particular method for creating those lesions is immaterial to the outcome. In other words, any energy source or technique that is capable of creating the correct lesion pattern and is uniformly transmural will result in a cure of AF in essentially all patients.

I have 2 questions for Dr Raman. Why do you think the results improved with time, because that has not been the experience in most other studies? Second, you note that there was no AF on long-term follow-up, but did those patients ever experience episodes of atrial flutter?

I congratulate Dr Raman and his associates on a well-designed and important study.

Dr Raman. Thank you very much, Dr Cox. It is a privilege to actually have you discuss this paper because you served as an inspiration for us to actually set up this protocol. I will answer the second question first. In terms of flutter, we had one patient who had one episode of flutter late, and it resolved spontaneously. This was asymptomatic flutter, and fortunately, the patient was actually reviewed at that time by his cardiologist and local doctor. On subsequent Holter monitoring, he was found to be in sinus rhythm, and therefore he did not actually need further medications or specific intervention. A few years ago this man ran marathons. He was in his 70s, and he went back to running up hills. He said he used to experience tachycardia or felt palpitations coming on when he ran up a hill, but he did not have this experience postoperatively, and I think this was a chance finding that he actually had flutter, which was relatively slow.

The first question concerns the improvement in AF over time. I think almost definitely that this procedure does nothing to reduce the propensity toward early postoperative AF. We all know that postoperative $\mathrm{AF}$ in patients undergoing any cardiac surgical procedure is about $30 \%$, and despite all the different manipulations, such as magnesium infusions and $\beta$-blockade, this still seems a bugbear. We did not see a difference. Early in the experience, we were very enthusiastic, and some of the surgeons applied these procedures in all kinds of patients. I think they have actually been a lot more selective later on. As our experience grew, we have also been more aggressive in using cardioversion early on, which might account for the improvement in the recovery of sinus rhythm. The other interesting thing, and this is an observation that we have seen, is that patients who have been followed up for 3 months who seem to be in fibrillation and then at the 6-month mark they have reverted to sinus rhythm. I know that this is anecdotal, but I have at least 3 patients with that, and other people have had similar experiences. I cannot explain it, but I think they seem to stabilize electrically with the passage of time.

Dr Joao Melo (Lisbon, Portugal). Congratulations on a beautiful paper. I am happy to see those results, which are much better than most reported results, including ours. But to understand whether we are comparing the same type of patients, I noticed that $25 \%$ of your patients were not in chronic AF. Therefore, it is important to know how many of your patients with mitral valve disease were part of this group of patients. My first question is to know whether this a selected population. My second question regards the issue of pacemakers because it is also very striking that you did your lines on the Cox maze concept and you are reporting no need for postoperative pacemakers. Can you elaborate on the reason for that finding?

Dr Raman. As I said, this is a reporting of what we have seen with this probe, and I cannot speak for specific indications in other centers, but all patients that had documented AF and came up initially for mitral valve surgery and later on for coronary artery surgery or early valve replacement surgery were enrolled, and as they got more familiar with the technique, they started getting more confident with it. I cannot tell you with the AF how many of them had mitral valve disease, but we will look at that carefully.

Dr Ralph Damiano (St Louis, Mo). I would like to echo both Dr Cox's and Dr Melo's congratulations on a beautiful study. One of the objectives of the maze procedure, or any type of surgery for $\mathrm{AF}$, is to allow patients to discontinue antiarrhythmic drugs, which have a high incidence of side effects. I noticed you did not mention 